\title{
Pesquisa de criptococose em cães atendidos no Hospital de Clínicas Veterinárias da UFRGS, Porto Alegre,Brasil*
}

\author{
Screening for cryptococcosis in dogs referred to the Hospital \\ de Clínicas Veterinárias of the UFRGS, Porto Alegre, Brazil \\ Izamara Aparecida de Oliveira ${ }^{1}$, Márcia de Oliveira Nobre $^{2} \&$ Laerte Ferreiro ${ }^{3}$
}

\begin{abstract}
RESUMO
A criptococose, micose causada por espécies encapsuladas do gênero Cryptococcus, acomete o homem e vários animais, podendo ocorrer em indivíduos imunocompetentes, mas freqüientemente está associada a um estado de comprometimento imunológico. A via mais freqüente de contaminação por esta levedura é a inalatória. Foi pesquisada a ocorrência do Cryptococcus em cães com sintomatologia respiratória e/ou neurológica, atendidos no Hospital de Clínicas Veterinárias da Universidade Federal do Rio Grande do Sul (UFRGS). A amostragem foi composta por 112 cães. O exame direto foi realizado em apenas 17 amostras de líquido cefalorraquidiano (LCR), e o cultivo em ágar níger (Guizotia abissynica) a $37^{\circ} \mathrm{C}$ durante dez dias, a partir de secreção nasal (112), sangue total (112) e LCR (n=17). Para a aglutinação em látex (LA), utilizou-se o kit Crypto-LA (Wampole), para testar soro $(n=112)$ e LCR $(n=17)$. O teste também foi realizado com tratamento prévio com pronase em 36 amostras (32 soros e 4 LCR). Os resultados dos exames direto, cultivo e LA foram negativos para o Cryptococcus em todas as amostras testadas. Apesar da negatividade dos resultados desta amostragem, é plausível a expectativa da ocorrência da infecção pelo Cryptococcus posto que, existe uma população canina constantemente exposta ao risco de se contaminarem com propágulos fúngicos, presentes nos excrementos de pombos que coabitam, em grande número, na região de abrangência do estudo.
\end{abstract}

Descritores: Cryptococcus, criptococose, leveduras, cães, aglutinação em látex.

\section{ABSTRACT}

Humans and animals exposed to these areas constitute a risk population. The most frequent route of contamination is by inhalation. This work had as objective verify the occurrence of encapsulated Cryptococcus in dogs with respiratory and/or neurological signs assisted at the Hospital de Clínicas Veterinárias (Veterinary Medical Teaching Hospital) of the Universidade Federal do Rio Grande do Sul (UFRGS) at Porto Alegre, Rio Grande do Sul, Brazil. The sampling was composed by 112 animals. Microscopic direct examinations of cerebrospinal fluid samples (17) were carried out with nigrosine. Nasal secretion ( $\mathrm{n}=112)$, total blood ( $\mathrm{n}=112)$ and cerebrospinal fluid $(\mathrm{n}=17)$ were cultivated in bird seed agar plates (Guizotia abissynica), and incubated at $37^{\circ} \mathrm{C}$ for up to ten days. The latex crypto-coccal antigen agglutination test (Crypto-LA; Wampole) was performed on serum ( $\mathrm{n}=112)$ and cerebrospinal fluid samples $(n=17)$. Also, a previous treatment was performed with pronase in 36 samples [serum $(n=32)$ and cerebrospinal fluid $(n=4)]$. The results of the direct exam, culture and agglutination test in latex were all negative for the presence of Cryptococcus. In spite of the results of this sampling, it is reasonable to expect the occurrence of the Cryptococcus infection, considering that, in the area of this sampling, the canine population is constantly exposed to the risk of cohabiting with a great population of pigeons.

Key words: Cryptococcus, Cryptococcosis, yeast, dogs, latex cryptococcal antigen agglutination test. 


\section{INTRODUÇÃO}

A criptococose é uma levedurose que acomete o homem e vários animais, podendo ocorrer em indivíduos imunocompetentes, mas freqüentemente está associada a um estado de comprometimento imunológico. $[1,2,10]$ Atualmente a etiologia desta micose é atribuída a três espécies: Cryptococcus neoformans, $C$. gattii e $C$. grubii [4].

Especificamente, em relação aos cães com criptococose, na maioria dos relatos, são observados sinais clínicos neurológicos e/ou oftálmicos [2,5,15]. O trato respiratório superior também é frequientemente envolvido [19]. Ocasionalmente, ocorre úlcera cutânea especialmente no nariz, nos lábios, na cavidade oral ou ao redor das unhas. Outros órgãos afetados, em menor proporção, são os rins, linfonodos, baço, fígado, tireóide, adrenal, pâncreas, ossos, trato gastrintestinal, músculo, próstata, miocárdio e válvulas cardíacas [23].

Os pequenos animais, principalmente os cães, constituem cada vez mais um importante elo na vida do ser humano urbano, o que gera uma crescente preocupação com a saúde e o bem estar destes animais. Devido à existência de poucos relatos na literatura sobre criptococose canina, um estudo sobre a ocorrência desta levedura foi conduzido em cães atendidos no Hospital de Clínicas Veterinárias (HCV) da Universidade Federal do Rio Grande do Sul (UFRGS).

O trabalho objetivou verificar uma possível relação entre cães com sinais clínicos respiratórios e/ou neurológicos, e a presença do Cryptococcus pesquisada através do exame direto com nigrosina (líquido cefalorraquidiano), do cultivo em ágar níger (secreção nasal, sangue total e líquido cefalorraquidiano) e do teste de Aglutinação em Látex (soro e líquido cefalorraquidiano).

\section{MATERIAIS E MÉTODOS}

A amostragem estudada foi composta por 112 cães [59 fêmeas (53\%) fêmeas e 53 machos (47\%)] atendidos na rotina do H.C.V.-UFRGS, no período de outubro de 2003 a maio de 2004. Os animais foram divididos em três grupos de acordo com a sintomatologia apresentada: respiratória $(\mathrm{n}=53 ; 47 \%)$, neurológica $(\mathrm{n}=$ $38 ; 34 \%)$ e com ambas sintomatologias $(\mathrm{n}=21 ; 19 \%)$.

Os animais da amostragem não apresentaram alterações cutâneas e oculares significativas, não sendo, portanto, classificados por estes sistemas.

A amostragem, quanto à raça dos animais, foi composta por $51(45,53 \%)$ cães SRD; $17(15,17 \%)$ Dachshund; 9 (8,03\%) Fila Brasileiro; 7 (6,25\%) Poodle e Rottweiler; 5 (4,46\%) Pastor Alemão; 4 (3,57\%) Cocker; 2 (1,78\%), Boxer, Husky, Labrador e Pit Bull; $1(0,89 \%)$, Akita, Collie, Pinscher e Weimaraner.

Foram utilizadas 112 amostras de secreção nasal obtidas através da utilização de escovas interdentais finas, as quais eram friccionadas no interior das narinas dos cães, e 112 amostras de sangue total da veia jugular. Também foram obtidas amostras de líquido cefalorraquidiano (LCR), mas devido ao fato do mesmo ser obtido por pressão e não por aspiração, se obteve somente 17 amostras. O LCR era acondicionado em tubos eppendorfs estéreis e centrifugado a $1000 \mathrm{rpm}$ por 10 minutos. O sobrenadante era armazenado em tubos eppendorfs estéreis.

O exame direto foi realizado a partir do LCR $(\mathrm{n}=17)$ entre lâmina-lamínula com nigrosina e o cultivo em ágar níger (Guizotia abyssinica), das amostras de secreção nasal, de sangue total e de LCR era incubado a $37^{\circ} \mathrm{C}$ por dez dias.

As amostras de soro e de LCR foram inativadas a $56^{\circ} \mathrm{C}$ por 30 minutos, e refrigeradas a $4^{\circ} \mathrm{C}$ por até 24 horas. O teste de Aglutinação em Látex foi realizado, utilizando-se o Crypto-LA ${ }^{1}$ Test. Dentre as amostras de soro, $32(28,57 \%)$, escolhidas aleatoriamente, foram testadas com e sem tratamento prévio com pronase. Do total de amostras de LCR, 4 (23,52\%), escolhidas aleatoriamente, também foram testadas com e sem tratamento com pronase. Para o tratamento foram utilizados $300 \mathrm{~mL}$ da amostra $+50 \mathrm{~mL}$ da pronase, colocadas em banho-maria a $56^{\circ} \mathrm{C}$ por 30 minutos e, após, se adicionava $50 \mathrm{~mL}$ do inibidor da pronase.

\section{RESULTADOS}

A levedura não foi observada tanto nos exames do líquido cefalorraquidiano, quanto nos cultivos das amostras de secreção nasal, sangue total e líquido cefalorraquidiano. Os testes de aglutinação em látex, nas amostras de soro e de líquido cefalorraquidiano, também foram todos negativos. Não ocorreu alteração na interpretação dos resultados nas amostras tratadas com pronase.

Proprietários de 59 cães foram entrevistados para traçar um perfil do ambiente onde estes viviam. Os potenciais de exposição da população amostrada a situações de risco de contrair a infecção, através de ambientes possivelmente contaminados, estão sumarizados na Tabela 1. Os animais foram classificados quanto a possibilidade ou ausência de contato com excretas de pássa- 


\begin{tabular}{|c|c|c|c|}
\hline Contato & $\begin{array}{c}\text { Excreta de } \\
\text { Pássaros em geral } \\
\mathrm{n}(\%)\end{array}$ & $\begin{array}{c}\text { Excreta de Pombos } \\
n(\%)\end{array}$ & $\begin{array}{c}\text { Acesso a Parques } \\
\mathrm{n}(\%)\end{array}$ \\
\hline Possível & $47(79,66)$ & $40(67,80)$ & $32(54,24)$ \\
\hline Ausente & $12(20,34)$ & $19(32,20)$ & $27(45,76)$ \\
\hline TOTAL & 59 & 59 & 59 \\
\hline
\end{tabular}

ros em geral, com excretas de pombos e quanto ao acesso a parques.

\section{DISCUSSÃO}

Em 1970, a criptococose foi denominada como um "sleeping giant" entre as micoses sistêmicas [1]. Com a pandemia da AIDS, a ocorrência e a severidade dos casos clínicos desta micose aumentaram consideravelmente, gerando diversas pesquisas sobre o assunto.

Em São Paulo, C. neoformans e C. gattii foram isolados de locais urbanos com uma alta densidade de pessoas circulando [24]. O Cryptococcus pode também ser encontrado em ocos de árvores, não estando associado á uma espécie de árvore em particular, mas sim a um nicho de biodegradação natural de madeira, fornecendo substrato para o crescimento da levedura $[16,17]$.

Crytococcus grubii já foi isolado a partir de acúmulo de fezes secas de pombos em prédio situado no centro de Porto Alegre [18]. Também já foi demonstrado o predomínio de amostras de $C$. grubii em isolados clínicos e ambientais de amostras do Rio Grande do Sul [4].

No Brasil, em animais de companhia, o primeiro caso de criptococose foi descrito em gato doméstico em 1971 [6]. Um estudo sobre a criptococose felina no Brasil, encontrou uma porcentagem de $8 \%$ de soropositivos à presença do antígeno capsular criptocócico em felinos com sinais clínicos sugestivos de criptococose e, também, $8 \%$ de soropositividade em felinos assintomáticos [8].

A infecção por FeLV e/ou FIV, pode constituir um fator predisponente para o desenvolvimento da criptococose felina [23]. O primeiro caso de criptococose disseminada por $C$. gattii foi relatado recentemente no Brasil, em um felino da raça siamês, positivo para FeLV [11].

$\mathrm{O}$ primeiro relato de criptococose canina no Brasil ocorreu em 1974 [7]. A partir da década de 80, casos esparsos, com diagnósticos intra-vitam e post morten, vêm sendo relatados em diversos estados brasileiros [2,5, $9,15,26,28]$.
Apesar destes poucos registros na literatura, acredita-se que o diagnóstico desta levedurose seja muito subestimado, visto que o agente é ubiquiitário e, também, porque os cães estão freqüentemente em contato direto com o habitat natural do Cryptococcus.

A amostragem testada foi composta principalmente por cães de população carente, que vivem em casas e sítios na periferia de Porto Alegre. A grande maioria destes animais estava constantemente exposta ao risco de infecção, sendo que oito proprietários relataram a presença de pombos no comedouro de seus cães e dois, moradores em prédios, referiram que as aves pousando em suas janelas e aparelhos de ar condicionado.

Um estudo retrospectivo sobre criptococose, constatou que de 38 cães: 63\% residiam em áreas suburbanas (com jardins, parques e árvores), 32\% em áreas rurais, e somente $5 \%$ em áreas urbanas (grande densidade populacional, sem jardins e parques) [25]. Com os resultados do presente trabalho, não foi possível relacionar grau de exposição a ambientes favoráveis a presença da levedura e ocorrência de criptococose em cães.

As amostras foram obtidas entre os meses de outubro de 2003 e maio de 2004, que são caracterizados por apresentarem altas temperaturas na região de abrangência do estudo. A literatura registra que altas temperaturas $\left(30^{\circ} \mathrm{C}\right)$ são menos favoráveis para a sobrevivência do Cryptococcus [31]. É necessário, portanto, verificar se existem influências sazonais na ocorrência desta micose.

Malik et al. [21], estudando uma população assintomática (56 cães abandonados em um abrigo), encontraram $14 \%$ de positividade no cultivo do lavado nasal. A diferença entre os resultados aqui apresentados e os supra citados, pode estar relacionada à amostragem estudada, já que aqueles autores testaram cães confinados em um mesmo local, onde poderia haver um foco infeccioso comum.

Talvez possam ter ocorrido resultados falsos negativos no cultivo, pois não foi realizado um lavado 
nasal para coleta de material, que seria ideal para a obtenção de uma amostra, mas que não foi realizado pela necessidade dos cães estarem anestesiados no momento da coleta.

A detecção do antígeno capsular é útil quando positivo, mas não é fidedigno para o diagnóstico de infecção limitada ao trato respiratório [29], enquanto que resultados falsos negativos na aglutinação em látex podem ocorrer se a levedura está presente em pequenas quantidades ou se o organismo não é bem capsulado [27]. Por esta razão, não se excluí, neste experimento, a possibilidade da ocorrência de resultados falsos negativos na prova de aglutinação em látex.

Resultados falsos positivos na aglutinação em látex podem ocorrer na presença de certas macroglobulinas que, normalmente, ocorrem no soro de humanos com artrite reumatóide, sarcoidose, cirrose, sífilis, psoríases, e lúpus eritematoso sistêmico [3]. A aglutinação não específica é detectada pelo uso de globulina normal reagente. A aglutinação em globulina normal reagente e em globulina anticriptocócica reagente requer diluição com ambos os reagentes [22]. Neste experimento, todas as amostras foram testadas com globulina normal reagente, não ocorrendo reação de aglutinação em nenhuma amostra.

A avaliação do uso da pronase para eliminar fatores de interferência na aglutinação em látex, como reações cruzadas, demonstrou um aumento na sensibilidade do teste [12].

A pronase degrada anticorpos e proteínas que se ligam e mascaram o antígeno, com subseqüente liberação dos polissacarídeos resultando em altos títulos na aglutinação [20,30]. O kit utilizado no experimento, CryptoLA $^{1}$ não contém esta enzima. Inicialmente foi testada uma amostragem $(n=36)$ para comparar dois procedimentos: com e sem tratamento prévio com pronase. Os testes indicaram não ocorrer diferenças nos resultados destas amostras, sendo todas negativas para o teste de aglutinação em látex.

A maioria dos cães era criada solta nos pátios de suas casas, entrando em contato direto com locais onde provavelmente haveria propágulos do Cryptococcus e, por consequiência, poderiam estar mais predispostos à infecção. O modo de contaminação é através da inalação da levedura, com posterior disseminação para outros tecidos [14].

A amostragem testada era composta por cães que apresentavam sinais clínicos de alteração respiratória e/ou neurológica e que poderiam estar com seu sistema imunológico deficiente. Muitos aspectos sobre a patogenia do Cryptococcus ainda não estão bem esclarecidos, incluindo o mecanismo de defesa que previne a passagem do estágio da colonização para o da disseminação [10].

Considera-se que a criptococose ocorra com menor frequiência nos cães, em relação aos gatos [19,23]. Os pequenos animais estão ganhando destaque na vida do ser humano urbano, principalmente os cães, que são adquiridos, muitas vezes, por facilitarem um maior contato social entre as pessoas. Também se verifica uma significativa população de pombos nas cidades, alojados em igrejas, prédios, parques e praças. Acredita-se que deve haver mais infecções subclínicas em cães e gatos [13].

\section{CONCLUSÃO}

Nesta amostragem não foi detectada relação entre cães com sinais clínicos respiratórios e/ou neurológicos e a presença Cryptococcus. Porém, apesar da negatividade dos resultados desta amostragem, é plausível a expectativa da ocorrência da infecção pelo Cryptococcus posto que, existe uma população canina constantemente exposta ao risco de se contaminar com propágulos fúngicos, presentes nos excrementos de pombos que coabitam, em grande número, prédios, parques e praças na região de abrangência do estudo.

Agradecimentos. À Spencer Sigmund Jang do Laboratory of Microbiology, Veterinary Medical Teaching Hospital (VMTH), University of California (UCD), Davis, CA/USA; Márcia dos Santos Lazéra do do Serviço de Micologia , Instituto de Pesquisa Clínica Evandro Chagas (IPEC), Fundação Oswaldo Cruz (FIOCRUZ), Rio de Janeiro/Brasil; Luiz Carlos Severo e Flávio Matos de Oliveira, Instituto de Pesquisa e Diagnóstico (IPD), Complexo Hospitalar Santa Casa de Misericórdia de Porto Alegre/Brasil.

\section{NOTA INFORMATIVA}

${ }^{1}$ Wampole Laboratories, Cranbury, N.J.

\section{REFERÊNCIAS}

1 Ajello L. 1970. The medical mycological iceberg. In: International Symposium on Mycoses. Washington: Scientific Publication, pp.3-12. 
2 Beheregaray W.K., Pöppl A.G., Hartfelder C.C., Landell M., Valente P., Oliveira I.A., Ferreiro L., Oliveira R.T., Machado M.L.S., Pigatto J.A.T., Ferreira R.R. \& Mello F.P.S. 2005. Criptococose em um cão com envolvimento de linfonodos, pele, olhos e glândula mandibular. Revista Universidade Rural, Série Ciências da Vida. 25(Supl): 252-253.

3 Bennett J.E. \& Bailey J.W. 1971. Control for rheumatoid factor in latex test for cryptococcosis. American Journal Clinical Pathology. 56: 360-365.

4 Casali A.K., Staats C.C., Schrank A. \& Vainstein M.H. 2001. Cryptococcus neoformans: aspectos moleculares e epidemiológicos. Biotecnologia Ciência \& Desenvolvimento 20: 34-37.

5 Cassali G.D., Nogueira R.H.G., Spiewak G. \& Moreira Y.K. 1991. Canine Cryptococcosis. Arquivo Brasileiro de Medicina Veterinária e Zootecnia. 43: 535-538.

6 Chagas W.A., Figueiredo J. B., Cruz L.C.H. \& Neves J.G. 1971. Criptococose cutânea em um gato Doméstico. Descrição de um caso. Revista Brasileira de Medicina Veterinária. 1: 5-12.

7 Chagas W.A., Figueiredo J.B., Neves J.G. \& Cruz L.C.H. 1974. Criptococose em cão: relato de um caso. In: Anais do $14^{\circ}$ Congresso Brasileiro de Medicina Veterinária (São Paulo, Brasil). p.117.

8 Chiesa S.C. 1998. Criptococose felina: aspectos clínicos-epidemiológicos. 94f. São Paulo, SP. Dissertação (Mestrado em Medicina Veterinária) - Programa de Pós-graduação em Clínica Veterinária. Faculdade de Medicina Veterinária e Zootecnia, Universidade de São Paulo.

9 Faria R.O., MeinerzA.R.M.,Antunes T.A., Cleff M.B., Nascente P.S., Souza L.L., Nobre M.O., LimaA.P. \& Meireles M.C.A. 2002. Isolamento de Cryptococcus sp. na área central da cidade de Pelotas-RS. In: Anais do XXII Congresso Brasileiro de Clínicos Veterinários e Pequenos Animais (Brasília, Brasil). 1 CD-ROM.

10 Feldmesser M., Tucker S. \& Casadevall A. 2001. Intracellular parasitism of macrophages by Cryptococcus neoformans. Trends in Microbiology. 9: 273-278.

11 Ferreiro L., LorettiA.P.,Appelt C.E. \& Oliveira F.M. 2001. Disseminated cryptococcosis caused by Cryptococcus neoformans var. gattii in an immunocompromised siamese cat: a case report. In: Anais do $3^{\circ}$ Congresso Brasileiro de Micologia (Águas de Lindóia, São Paulo). p.129.

12 Gray L.D. \& Roberts G.D. 1988. Experience with the use of pronase to eliminate interference factors in the latex agglutination test for cryptococcal antigen. Journal of Clinical Microbiology. 26: 2450-2451.

13 Ikeda R., Tamura M. \& Shinoda T. 2000. Persistence of cryptococcal antigenemia in a infected dog and uninfected rabbits. Medical Mycology. 38: 85-89.

14 Kwon-Chung K.J., Sorrell T.C., Dromer F., Fung E. \& Levitz S.M. 2000. Cryptococcosis: clinical and biological aspects. Medical Mycology. 38: 205-213.

15 Larsson C.E., Otsuka M., Michalany N.S., Barros P.S.M., Gambale W. \& Safatle A.M.V. 2003. Criptococose canina: relato de caso. Arquivo Brasileiro de Medicina Veterinária e Zootecnia. 55: 533-538.

16 Lazéra M.S., Pires F.D.A., Camillo-Coura L., Nishikawa M.M., Bezerra C.C., Trilles L. \& Wanke B. 1996. Natural habitat of Cryptococcus neoformans var. neoformans in decaying wood forming hollows in living trees. Journal of Medical \& Veterinary Mycology. 34: 127-131.

17 Lazéra M.S., Cavalcanti M.A.S., LonderoA.T., Trilles L., Nishikawas M.M. \& Wanke B. 2000. Possible primary ecological niche of Cryptococcus neoformans. Medical Mycology. 38: 379-383.

18 Machado C.C., Amaral A.A. \& Severo L.C. 1993. Cryptococcus neoformans var. neoformans isolado do solo. Revista do Instituto de Medicina Tropical de São Paulo. 35: 77-79.

19 Malik R., Dill-Macky E., Martin P., Wigney D.I., Muir D.B. \& Love D.N. 1995. Cryptococcosis in dogs: a retrospective study of 20 consecutive cases. Journal of Medical \& Veterinary Mycology. 33: 291-297.

20 Malik R., McPetrie R., Wigney D.I., Craig A.J. \& Love D.N. 1996. A latex cryptococcal antigen agglutionation test for diagnosis and monitoring of therapy for cryptococcosis. Australian Veterinary Journal. 74: 358-364.

21 Malik R., Wigney D.I., Muir D.B. \& Love D.N. 1997. Asymptomatic carriage of Cryptococcus neoformas in the nasal cavity of dogs and cats. Journal of Medical \& Veterinary Mycology. 35: 27-31.

22 Medleau L., Marks M.A. \& Brown J. 1990. Clinical evaluation of cryptococcal antigen latex agglutination test for diagnosis of cryptococcosis in cats. Journal of American Veterinary Medical Association. 196: 1470-1473.

23 Medleau L. \& Barsanti J.A. 1990. Cryptococcosis. In: Greene C.E.(Ed). Infectious Diseases of the Dog and Cat. Philadelphia: Saunders, pp.687-695.

24 Montenegro H. \& Paula C.R. 2000. Environmental isolation of Cryptococcus neoformans var. gattii and C. neoformans var. neoformans in the city of São Paulo, Brazil. Medical Mycology. 38: 385-390. 
25 O'Brien C.R., Krockenberger M.B., Wigney D.I., Martin P. \& Malik R. 2004. Retrospective study of feline and canine cryptococcosis in Australia from 1981 to 2001: 195 cases. Medical Mycology. 42: 449-460.

26 Ribeiro C., Silveira J.M. \& Ferreira M.L. 1983. Criptococose canina em Mato Grosso do Sul - descrição de um caso. In: Anais do $6^{\circ}$ Congresso Brasileiro de Clínica Veterinária de Pequenos Animais (São Paulo, Brasil). Não paginado.

27 Richardson M.D. \& Warnock D.W. 1993. Cryptococcosis. In: Fungal infection diagnosis and management. London: Blackwell Scientific, pp.115-122.

28 Roehe P.M. \& Pianta C. 1985. Cryptococcus neoformans como causa de encefalite em cão. Arquivos da Faculdade de Veterinária UFRGS. 13: 23-27.

29 Saubolle M.A. 2001. Micologia e o laboratório clínico no diagnóstico das micoses respiratórias. In: Sarosi G.A. \& Davies S.F. (Eds). Doenças fúngicas do pulmão. 3.ed. Rio de Janeiro: Revinter, pp.1-16.

30 Stockman L. \& Roberts G.D. 1983. Specificity of the latex test for cryptococcal antigen: a rapid, simple method for eliminating interference factors. Journal of Clinical Microbiology. 17: 945-947.

31 Théraud M., Gangneux J.P., Preney L. \& Guiguen C. 2003. Comparative survival of clinical and environmental isolates of Candida albicans and Cryptococcus neoformans in natural and experimental conditions. Journal de Mycologie Médicale. 13: 93-97. 